\title{
Endoscopic Endonasal Pituitary Surgery: Outcome analysis of 32 cases
}

\author{
Islam MR ${ }^{1}$, Ahmed $\mathrm{M}^{2}$, Hasan $\mathrm{MR}^{3}$, Mehbub $\mathrm{H}^{4}$, Ashfaq $\mathrm{M}^{5}$
}

Conflict of interest: There is no conflict of interest relevant to this paper to disclose.

Funding Agency : was not funded by any institute or any group.

Contribution of Authors : Principal Investigator- Dr. Md. Rafiqul Islam

Manuscript preparation- Dr. Monsur Ahmed

Data collection- Dr. Md. Rashidul Hasan, Dr. Hasan Mehbub

Editorial formatting- Dr. Musannah Ashfaq

Copyright: @2020bang.BJNS published by BSNS. This article is published under the creative commons CC-BY-NC license. This license permits use distribution (https://creativecommons. orgf/licences/by-nc/4-0/)reproduction in any medium, provided the original work is properly cited and is not used for commercial purposes.

Received: 10.08 .2020

Accepted: 15.10 .2020

\begin{abstract}
:
Introduction: Microsurgical trans-sphenoidal surgery for pituitary tumors has been standard treatment for nearly of century and was established by Harvey Cushing in the early twentieth century. Today, endoscopy is increasingly accepted in the treatment of pituitary lesions. In this article we analysed the surgical technique and outcome of 32 patients retrospectively with pituitary lesions treated with endoscopic endonasal trans-sphenoidal approach.
\end{abstract}

Material \& Methods: Between January 2016 to July 2020, 32 patients (22 female and 10 male) with pituitary tumors were operated using endoscopic endonasal transsphenoidal procedure without any nasal speculum. Post-operative nasal packing given in both nostril in all cases. The follow-up period ranged from 3 to 24 months.

Results: Among the 32 patients gross total tumor removal was achieved in 23 cases (71.87\%), subtotal removal done in 9 cases (28.13\%). Post-operative discomfort was minimal and hospitalization was 7-10 days. 10 patients developed post-operative transient diabetes insipidus, among them persisting DI occur 2 patients for further 3 months. No patient died in our series within follow up period.

Conclusion: Endoscopic endonasal trans-sphenoidal approach for removing pituitary lesions is a form of minimally invasive skull base surgery with excellent post-operative results.

Key Words: Endoscopy; Endonasal trans-sphenoidal approach, Pituitary surgery, Skull base surgery.

Bang. J Neurosurgery 2021; 10(2): 185-191

\section{Introduction:}

The evolution of neurosurgery in last century has passed from the use of wide craniotomies to smaller and further smaller approaches (keyhole concept), with the aim of reducing surgical trauma and of improving post-operative outcome.1,2 Microsurgical transsphenoidal surgery for pituitary tumors has been standard therapy for decades, established by Harvey Cushing in the early twentieth century. ${ }^{3-5}$ Since the introduction of the endoscope, adopted in paranasal sinus surgery by the otorhinolaryngologist. 6,7 and in other neurosurgical procedures, ${ }^{8-11}$ interest has developed regarding its use in trans-sphenoidal pituitary surgery. ${ }^{12-16}$ Although the microsurgical trans-sphenoidal approach, via a septal or sublabial incision, has been the operative technique of choice, endoscopy is increasingly accepted method to provide a closer detail of the anatomy and wider angles of view. The endoscopic endonasal trans-sphenoidal approach for pituitary lesions avoids the use of a nasal speculum and trans- sphenoidal retractor. ${ }^{17,18}$ This technique is a minimally invasive and maximally

1. Dr. Md. Rafiqul Islam, Associate Professor, Department of Neurosurgery, Dhaka Medical College \& Hospital, Dhaka, Bangladesh.

2. Dr. Monsur Ahmed, Assistant Professor, Department of Neurosurgery, National Institute of Neuroscience and Hospital, Dhaka, Bangladesh.

3. Dr. Md. Rashidul Hasan. Medical Officer, Department of Neurosurgery, Dhaka Medical College \& Hospital, Dhaka, Bangladesh.

4. Dr. Hasan Mehbub, Registrar, Department of Neurosurgery, National Institute of Neuroscience and Hospital, Dhaka, Bangladesh.

5. Dr. Musannah Ashfaq, Resident, Department of Neurosurgery, Dhaka Medical College \& Hospital, Dhaka, Bangladesh.

Address of Correspondence: Dr. Md. Rafiqul Islam, Associate Professor, Department of Neurosurgery, Dhaka Medical College \& Hospital, Dhaka, Bangladesh. Mobile: +8801713044479, e-mail:rislam566@yahoo.com 
effective neurosurgical treatment for patients with pituitary tumors. In the present study we analysed efficacy and safety of the surgical procedure for endoscopic endonasal trans-sphenoidal surgery and the outcome of 32 patients with tumors of the intra-, para-, and suprasellar regions treated in department of neurosurgery, Dhaka Medical College and in others private hospitals in Dhaka, Bangladesh from January 2016 until July 2020.

The objective of this study to assess the outcome of endoscopic endonasal pituitary surgery

The specific objectives to evaluate the patient preoperatively, pre-operative optimization for surgery, Assessment of pros and cons of operative technique, Post-operative assessment for complications and follow up.

\section{Material and Methods}

\section{Study Procedure}

All patients with pituitary tumor underwent endoscopic endonasal trans-sphenoidal procedure between January 2016 to July 2020 were enrolled in the study. Pre-operative optimization with endocrine, opthalmological and radiological evaluation done. Patient were followed up with MRI, endocrinological and ophthalmological assessment after 3, 6, 12 and 24 months.

\section{Surgical technique}

General anesthesia with well packed gauze roll in oropharyngeal region to prevent post-operative blood and ûuid aspiration is the choice in endoscopic endonasal surgery. The patient was positioned in the supine with neutral head position with $15^{\circ}$ turn to the left. The nasal cavities were packed with adrenaline soaked merocele. Video apparatus equipment with a digital 3-chip mini-video camera connected to the $0^{\circ}$ endoscope allowed the surgeon to view the surgery. No nasal speculum was used. At first lateralization of inferior turbinate was done followed by right middle turbinectomy and left middle turbinate dissection to get a bi-nostril corridor. A debrider was used to remove the soft tissue before drilling of sphenoid sinus. Identification of sella and para seller structure was always possible at the posterior wall of the sphenoid sinus when looking in a cranio-caudal direction, identification of the planum sphenoidale, the sella turcica and the clivus was possible. In a rostro-caudal direction at the lateral walls of the sphenoid sinus, the optic protuberance, the optico-carotid recess and the carotid protuberance were identified (Fig.1). Opening of the sellar floor with a high-speed drill (special pituitary burr), enlargement with Kerrison's forceps. Then identification of carotid was done by micro doppler. Incision of dura was made in crisscross fashion. The lesion was removed with slow, circular movements using curettes and a suction device. Biopsy was taken fast by pituitary rongeur. At the end of the removal, a $30^{\circ}$ endoscope was used to search for any remaining tumor tissue in the intrasellar space. Sella reconstruction performed by gasket seal technique. At the end of the procedure, blood from the orotracheal region was suctioned. We used merocele pack for both nose and kept it for 48 hours.

\section{Results:}

Surgery using a totally endoscopic endonasal transsphenoidal technique was performed via a bi-nostril approach as described above in 32 patients. Postoperative discomfort such as pain, vomiting or dizziness was minimal and hospital stay was 7-10 days. This was evaluated by direct questionnaires and nursing notes. Ten patients developed diabetes insipidus during the post-operative course: eight was temporary, whereas in two it persisted for about 3 months, requiring oral vasopressin therapy. Among 32 pituitary adenoma total tumor removal was achieved in $23(71.87 \%)$ patients, subtotal $9(28.13 \%)$ patients, as shown on post-operative CT scan. 18 patients have pre-operative pituitary insufficiency and need post-operative thyroxine and steroid supplement. There was no malignant case in this series. Routine pathological studies were performed in all cases. Histopathological examination demonstrated 18 non function pituitary adenoma, 9 prolactinoma, 4 growth hormone secreting tumor and 1 cases follicle stimulating hormone. Among 18 patients with nonfunctional pituitary adenoma gross total removal was achieved in 12 patients, 16 patients presented with progressive visual impairment. With pre-operative normal pituitary function 2 developed post-operative partial insufficiency and 12 had normal function. Assuming post-operative hypopituitarism would occur after removal of large tumor patients were treated empirically with steroids until the first endocrine evaluation. Nasal cavity examination was performed in each follow-up. They were also questioned about their usual normal breaths. In the endoscopic examination no patient had synechia in the nasal mucosa or infection in the nasal-sphenoidal-Sella complex. 3 Patient develop CSF leak due to extension 


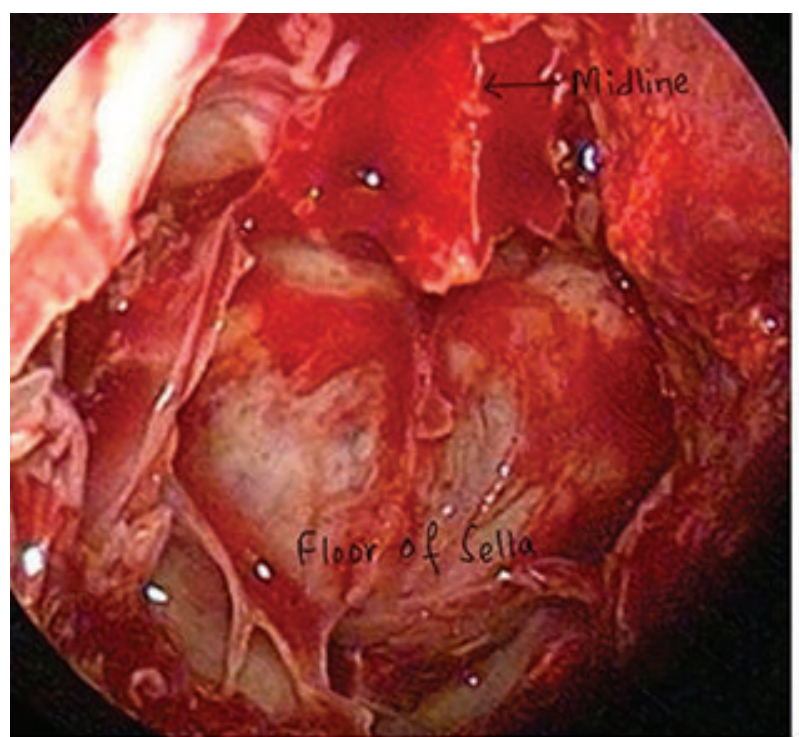

A

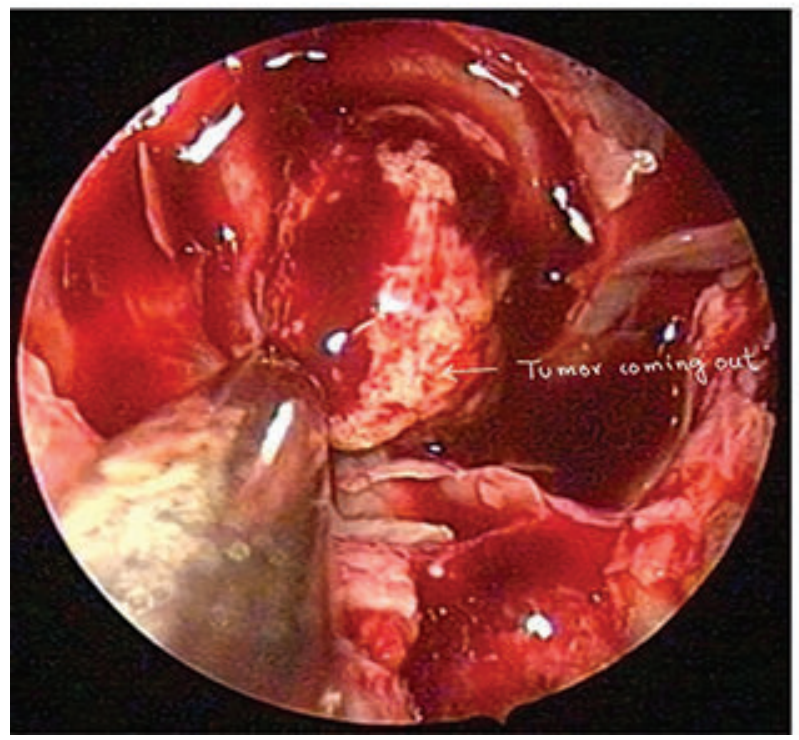

C

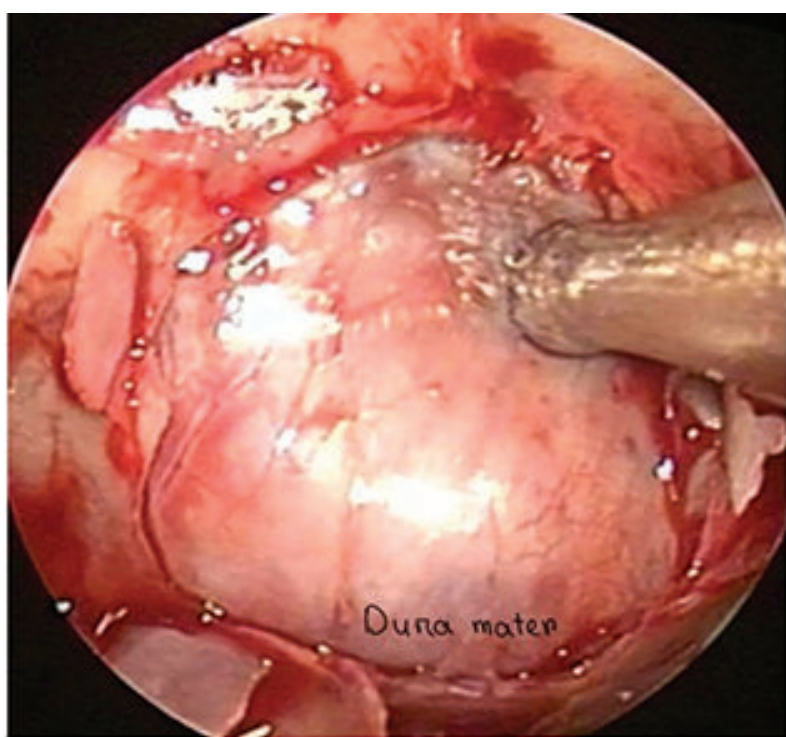

B

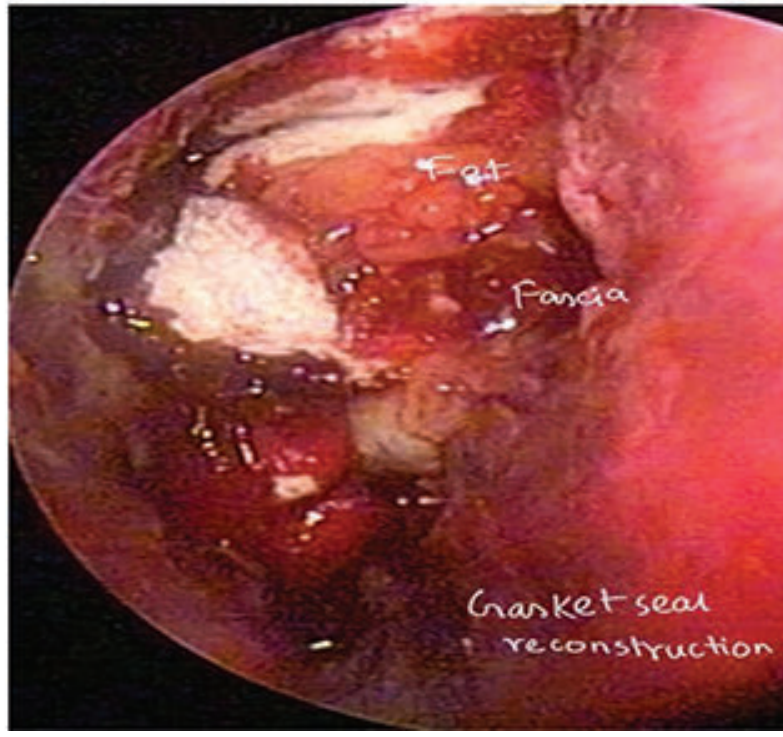

D

Fig-1: Per operative photograph showing different stages of procedure. A) sellar floor; B) After drilling visualization of dura; C) Tumor removal; D) Sellar reconstruction

of tumor into suprasellar space and tumor perforation of the diaphragma sella. These were treated conservatively. One patient needed lumber drain. The 32-patients continued had higher cortisol levels but without other abnormality of pituitary gland function. Post-operative MRI showed residual tumor in the cavernous sinus, which was advised for gamma knife radiosurgery.

Nine patients had prolactinoma among them 2 patients receive medical treatment before surgery.
Gross total removal done in 6 patient and rest 3 were advised to receive medical management post operatively. Four growth hormone producing adenomas operated among them no one received medical management. Complete removal done in all cases with post-operative reduction of growth hormone level in two of them. One patient had FSH producing tumor without pituitary gland insufficiency post-operative FSH level was normal and no impairment of pituitary gland function occurred. 

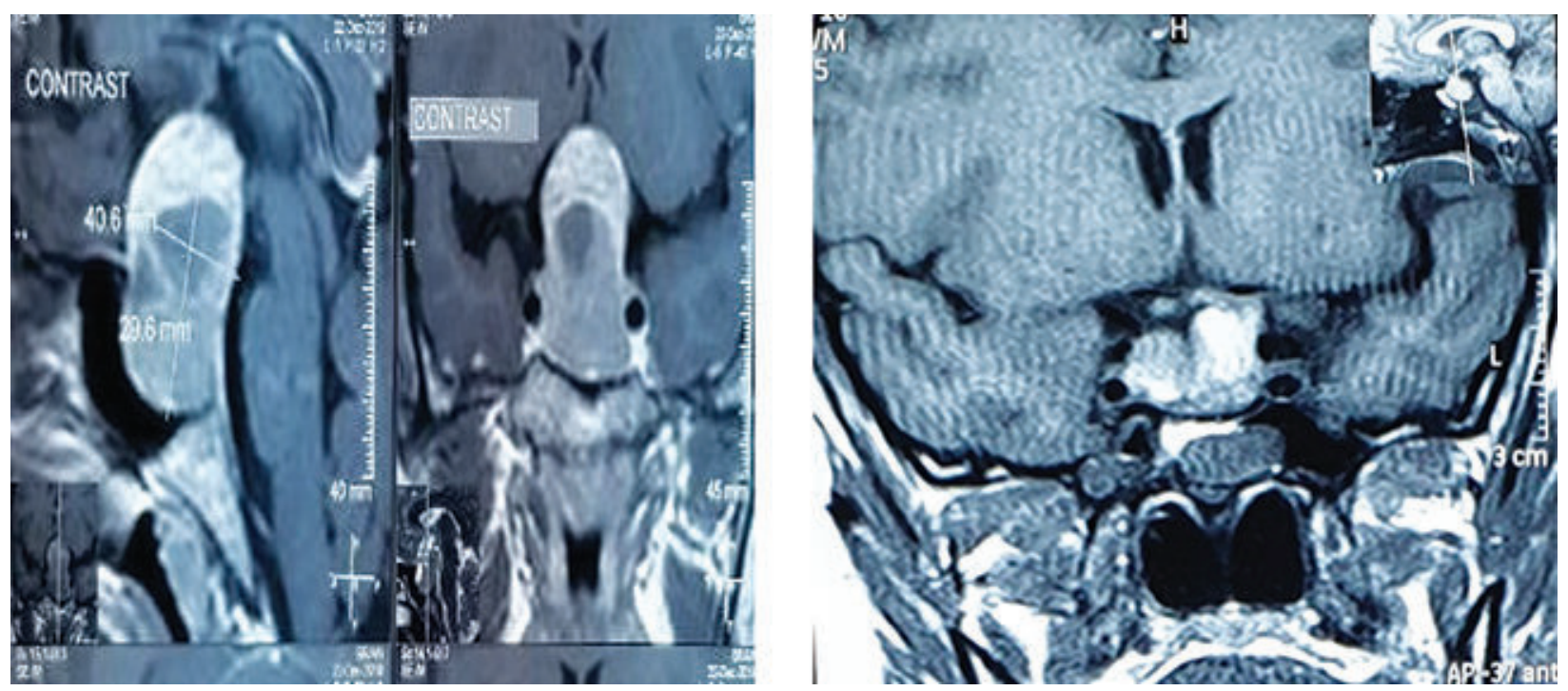

Fig-2. Preoperative T1-weighted, contrast, enhanced MRI scan from a patient with non-functioning pituitary tumor
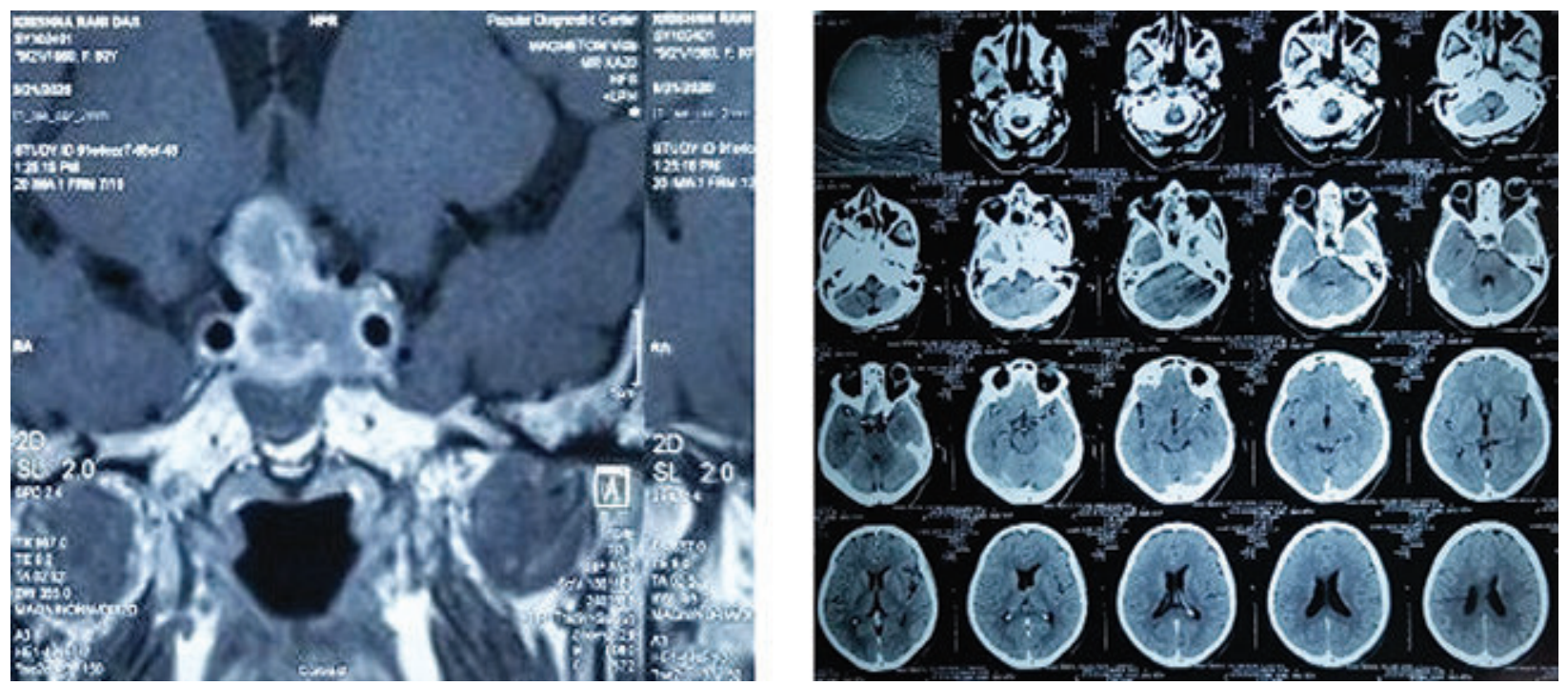

Fig-3. Preoperative contrast MRI scan from a patient with post-operative contrast CT showing complete tumor removal

Table-I

Endocrine function of the pituitary gland of 32 patients pre- and 3 months post-operatively

\begin{tabular}{lcccccc}
\hline Function of pituitary gland & \multicolumn{2}{c}{ Preoperative } & & \multicolumn{2}{c}{ Post-operative (3 motnhs) } \\
\cline { 2 - 3 } \cline { 6 - 7 } & $\mathrm{N}$ & & $\%$ & & $\mathrm{~N}$ & $\%$ \\
\hline Normal pituitary function & 14 & 43.75 & & 12 & 37.50 \\
Pituitary insuûciency & 18 & 56.25 & & 20 & 62.50 \\
\hline Total & 32 & 100 & & 32 & 100 \\
\hline
\end{tabular}


Table-II

Endocrinological results of 14 patients with hormone secreting tumors

\begin{tabular}{lcc}
\hline Tumor diagnosis & \multicolumn{2}{c}{$\begin{array}{c}\text { months post-operative hormonal } \\
\text { secretion levels of tumor }\end{array}$} \\
\hline Prolactin & 9 & High \\
Growth hormone & 4 & 2 \\
Follicle stimulating hormone & & 2 (patient is under evaluation \\
for re-operation) \\
\end{tabular}

\section{Discussion:}

During the twentieth century trans-sphenoidal endoscopic surgery has been the procedure of choice for almost all pituitary lesions. ${ }^{3,4}$ In 1987 Griffith and Veerapen first reported an endonasal trans-sphenoidal approach to the sellar region, which is now very popular and widely used for trans-sphenoidal surgery, often with endoscopic assistance. ${ }^{19}$ In the 1990 s the endoscope was adopted in pure endoscopic. ${ }^{9,10,20}$ or endoscope-assisted neurosurgical procedures. ${ }^{8,11}$ Jho and Carrauled this innovation for pituitary surgery. ${ }^{15,17,21}$ They ûrst describe an endoscope assisted endonasal trans-sphenoidal approach (15). The advantage for this procedure is improved wide angled visualization with elimination of the rigid tube, the nasal speculum, and replacement with its much more versatile virtual section at the level of the enlarged sphenoid ostium. ${ }^{23}$ In our surgical experience, endonasal endoscopy in comparison to microsurgical trans-nasal techniques gives the surgeon a wider surgical field, enabling safer interaction with neurovascular structures lying inside the sphenoid sinus at the lateral walls (carotid arteries, cavernous sinus) and in the intrasellar and suprasellar regions. The surgery starts with the enlargement of the sphenoid ostium, so there is no incision in the nasal mucosa or the gingiva. This leads to a low incidence of nasal-sinusial complications as showed in our results after otolaryngological examination and patient questionnaires. Treatment of recurrences is much easier after endoscopic surgery, as scars and adhesions do not occur post-operatively. The potential for tumor removal is greater with introduction of the endoscope inside the sella due to better visualization of the structures. The surgical field has broad lateral vision and movements are not limited by the tubular channel created by the nasal speculum. The tumor tissue-gland and diaphragma distinction is easier and better identification of holes in the cistern can be achieved. Gentle use of curved suction devices to remove tumor tissue as opposed to healthy pituitary gland under the endoscope seems to be much clearer than under the microscope. The surgical trauma to the normal pituitary gland appears to be minimal. Using a $30^{\circ}$ endoscope, excellent visualization of the diaphragma sella and suprasellar structures with their arachnoid membranes, facilitating complete tumor removal is possible. Our surgical results show a greater improvement in the pituitary gland function, with excellent post-operative course, minimal immediate respiratory dificulties, total tumor removal and minimal complications compared with large, historical microsurgical trans-sphenoidal series such as that by Ciric et al. ${ }^{24}$ a good view of the surgical target, adequate preservation of all structures around the lesion (pituitary gland and stalk, suprasellar cistern, cavernous sinus and its contents), and the integrity of the anatomical pathway used to reach the tumor ${ }^{25}$. It is our opinion that a cautious strategy determines partial or total removal and not the technique itself. At the same time the increased vision offered by the endoscope permits removal of the lesion under better visualization, thus contributing to a reduction in the incidence of complications. The surgeon's approach, whether a microscope or an endoscope is used, is a determinant both of the completeness of lesion removal and the complication rate ${ }^{25}$. The distinctive features of each procedure contribute to the final outcome, in terms of results and complications. Endoscopic endonasal pituitary surgery differs from trans-sphenoidal microsurgery in the following ways: in the different viewing instruments that are used for the operation, that is, the microscope or the endoscope, with three-dimensional vision offered by the microscope and with wider and close-up vision 
permitted by the endoscope; in that no nasal speculum is used in the pure endoscopic technique; and in that the endoscopic approach is endonasal, whereas the microsurgical one is often trans-nasal. The best strategy for dealing with complications is to avoid them. This depends on understanding the disease, the surgery and the techniques needed to obtain the optimal results. The approach analysed here, which we favor, conforms to these principles and may decrease the complication rate. Disadvantages of endonasal endoscopic pituitary surgery include the need for specialized surgical instruments, and lack of experience with the endoscopic techniques in neurosurgery; a sharp, and at the first procedures frustrating, learning curve with initially longer operative times; absolute necessity of excellent intraoperative hemostasis; and lack of 3-dimensional vision. Using the endoscope as a viewing instrument during surgery means that while the surgeon works in one direction, the visual information on the monitor is in a completely different direction. To provide a simultaneous observation of both endoscopic image and hand movements, we displayed the image on a screen placed in front of the surgeon. Surgical instruments without a bayonetshape (long and straight with safe grips) were developed for use in the nasal-sphenoidal-sellar complex. ${ }^{26}$ to solve the problem of interaction from the same nostril in a small corridor with the endoscope. Future developments in technical skills will allow simplification of endonasal endoscopic surgery and will become the method of choice for trans-sphenoidal pituitary surgery.

\section{Limitations of the Study}

This was a Retrospective type of study in a single community with comparatively small number of sample size. So, the study result may not reflect the exact scenarios of the whole country.

\section{Vii Conclusion and Recommendations}

The endoscopic endonasal trans-sphenoidal approach for removing pituitary lesions is a form of minimally invasive keyhole neurosurgical technique. It allows in maximal effective treatment with minimal trauma the nasal- sphenoidal-sellar complex.

Ethical approval: The study was approved by the Institutional Ethics Committee

\section{References:}

1. Cappabianca P, Alûeri A, Colao A, et al. Endoscopic endonasal trans-sphenoidal surgery in recurrent and residual pituitary adenomas: technical note. Minim Invasive Neurosurg 2000;43: 38-43.

2. Cappabianca P, Cavallo LM, de Divitiis E. Endoscopic endonasal trans-sphenoidal surgery. Neurosurgery 2004;55:933-40, discussion 940-41.

3. Adams CB, Burke CW. Current modes of treatment of pituitary tumours. Br J Neurosurg 1993;7:123-7.

4. Black PM, Zervas NT, Candia GL. Incidence and management of complications of trans-sphenoidal operation for pituitary adenomas. Neurosurgery 1987;20:920-4.

5. Hardy J. Trans-sphenoidal microsurgery of the normal and pathological pituitary. Clin Neurosurg 1969;16:185217.

6. Stammberger H. Endoscopic endonasal surgery-concepts in treatment of recurring rhinosinusitis. Part I. Anatomic and pathophysiologic considerations. Otolaryngol Head Neck Surg 1986;94:143-7.

7. Stammberger $\mathrm{H}$. Endoscopic endonasal surgery-concepts in treatment of recurring rhinosinusitis. Part II. Surgical technique. Otolaryngol Head Neck Surg 1986;94:147-56.

8. Fries G, Perneczky A. Endoscope-assisted brain surgery: part 2- analysis of 380 procedures. Neurosurgery 1998;42:226-31, discussion 231-2.

9. Fries G, Perneczky A. Intracranial endoscopy. Adv Tech Stand Neurosurg 1999;25:21-60.

10. Grunert P, Perneczky A, Resch K. Endoscopic procedures through the foramen interventriculare of Monro under stereotactical conditions. Minim Invasive Neurosurg 1994;37:2-8.

11. Perneczky A, Fries G. Endoscope-assisted brain surgery: part 1- evolution, basic concept, and current technique. Neurosurgery 1998;42:219-24., discussion 224-5.

12. Gamea A, Fathi M, el-Guindy A. The use of the rigid endoscope in trans-sphenoidal pituitary surgery. J Laryngol Otol 1994;108:19-22.

13. Helal MZ. Combined micro-endoscopic trans-sphenoid excisions of pituitary macroadenomas. Eur Arch Otorhinolaryngol 1995;252:186-9.

14. Carrau RL, Jho HD, Ko Y. Trans-nasal-trans-sphenoidal endoscopic surgery of the pituitary gland. Laryngoscope 1996;106:914-8.

15. Jho HD, Carrau RL. Endoscopy assisted trans-sphenoidal surgery for pituitary adenoma. Technical note. Acta Neurochir (Wien) 1996;138: 1416-25.

16. Wurster CF, Smith DE. The endoscopic approach to the pituitary gland. Arch Otolaryngol Head Neck Surg 1994;120:674.

17. Jho HD, Carrau RL. Endoscopic endonasal transsphenoidal surgery: experience with 50 patients. J Neurosurg 1997;87:44-51. 
18. Jho HD, Alûeri A. Endoscopic trans-sphenoidal pituitary surgery: various surgical techniques and recommended steps for procedural transition. $\mathrm{Br} \mathrm{J}$ Neurosurg 2000;14:432-40.

19. Griûth HB, Veerapen R. A direct trans-nasal approach to the sphenoid sinus. Technical note. J Neurosurg 1987;66:140-2.

20. Resch KD, Perneczky A, Tschabitscher M, et al. Endoscopic anatomy of the ventricles. Acta Neurochir Suppl 1994;61:57-61.

21. Jho HD, Carrau RL, Ko Y, et al. Endoscopic pituitary surgery: an early experience. Surg Neurol 1997:213-22, discussion 222-3.

22. Jho HD, Park IS, Alûeri A. The future of pituitary surgery. Clin Neurosurg 2000;47:83-98.
23. de Divitiis E, Cappabianca P. Endoscopic endonasal transsphenoidal surgery. Adv Tech Stand Neurosurg 2002;27:137-77.

24. Ciric I, Ragin A, Baumgartner C, et al. Complications of transsphenoidal surgery: results of a national survey, review of the literature, and personal experience. Neurosurgery 1997;40:225-36, discussion 236-7.

25. Cappabianca P, Cavallo LM, Colao A, et al. Surgical complications associated with the endoscopic endonasal trans-sphenoidal approach for pituitary adenomas. J Neurosurg 2002;97:293-8.

26. Cappabianca P, Alûeri A, Thermes S, et al. Instruments for endoscopic endonasal trans-sphenoidal surgery. Neurosurgery 1999;45: 392-5, discussion 395-6. 